\title{
Chemical characterization and spectroscopic analysis of the solubilization products from wheat straw produced by Streptomyces strains grown in solid-state fermentation
}

\author{
M. J. Hernández-Coronado, ${ }^{1}$ M. Hernández, ${ }^{1}$ F. Centenera, ${ }^{1}$ \\ M. I. Pérez-Leblic, ${ }^{1}$ A. S. Ball ${ }^{2}$ and M. E. Arias ${ }^{1}$
}

Author for correspondence: M. E. Arias. Tel: +91 885 4633. Fax: +91 8854623. e-mail: MPMAF@ALCALA.ES

1 Departamento de Microbiología y Parasitología, Universidad de Alcalá de Henares, 28871 Alcalá de Henares, Madrid, Spain

2 Department of Biological and Chemical Sciences, University of Essex, Wivenhoe Park, Colchester CO4 3SQ, UK

\begin{abstract}
The effects of two extraction procedures on the yield and properties of APPL (acid-precipitable polymeric lignin, or solubilized lignocellulose) produced by four streptomycetes during growth in solid-state fermentation were examined. When APPL was extracted with $\mathrm{NaOH}(0.1 \mathrm{M})$ rather than distilled water, yields increased threefold, with Streptomyces chattanoogensis exhibiting maximum solubilization levels [163 mg product (g straw) $^{-1}$ ]. Alterations in the characteristics of APPL obtained during extraction with NaOH were detected using cross-polarization and magic-angle spinning (CPMAS) ${ }^{13} \mathrm{C}$ NMR and IR spectroscopy and by GC-MS analysis after CuO oxidation, with the most significant changes detected in the cinnamic acid and lignin moieties. When APPL was extracted with $\mathrm{NaOH}$, ester links between hemicellulose and lignin and between hemicellulose and cinnamic acid were cleaved, resulting in a decrease in the alkyl and carbonyl groups attached to lignin, enabling greater solubilization. Yields of APPL extracted with water were lower, but spectral characterization of this APPL suggested a possible role for actinomycete peroxidases and phenolic acid esterases in lignin solubilization. For industrial solubilization of lignocellulose, a possible role for the application of streptomycetes, or their enzymes, in alkali extraction is suggested as a means of increasing solubilization levels.
\end{abstract}

Keywords : streptomycetes, acid-precipitable polymeric lignin, lignocellulose degradation

\section{INTRODUCTION}

There is considerable interest in the biological degradation of lignocellulose in the environment and its potential for industrial application. The biotechnological potential of waste biomass bioconversion has centred upon the biological and chemical treatment of lignocellulosic material to produce a range of products, including ethanol and sugars (Hartley et al., 1987). Also, the transformation of wheat straw during the growth of micro-organisms under solid-state fermentation conditions has been examined for the upgrading of straw to

Abbreviations: APPL, acid-precipitable polymeric lignin; CPMAS, crosspolarization and magic-angle spinning; $G$, guaiacyl; $H$, hydroxyphenyl; $S$, syringyl. produce pulps and animal feed (for a review see Dart \& Betts, 1991). The potential role of lignocellulosedegrading enzymes in the bleaching of pulp for paper has been investigated as an alternative or supplement to chemical bleaching techniques, which cause environmental problems through the release of chlorinecontaining effluents. Among the micro-organisms screened for the production of suitable enzymes, the actinomycetes are a group that have often been selected (Winter et al., 1991; Zhou et al., 1993).

Actinomycetes produce a range of hydrolytic and oxidative enzymes which act co-operatively in degradation of the lignocellulose complex during primary growth (Ball et al., 1990). The mechanisms involved in this degradation process have not yet been fully elucidated; however, the main role attributed to these micro- 
organisms is solubilization rather than depolymerization and mineralization of lignin (McCarthy, 1987). The main product of solubilization of wheat straw and other lignocellulosic residues by actinomycetes is an acid-precipitable polymeric lignin (APPL; Crawford et al., 1983). This polymeric material is composed mainly of lignin but also contains carbohydrate, protein and ash (McCarthy, 1987). Previous studies have shown that the chemical composition of the APPL is dependent on the fermentation (submerged or solid-state) and on the method used for its extraction from culture supernatants (Borgmeyer \& Crawford, 1985; Crawford et al., 1983).

A range of degradative techniques (acidolysis, manganate oxidation, alkaline ester hydrolysis, thioacidolysis) (Crawford \& Pometto, 1988) has been used along with non-degradative techniques (NMR and IR) (Seelenfreund et al., 1990; Crawford et al., 1983; McCarthy et al., 1986; Trigo \& Ball, 1994) to analyse APPL composition. Cupric oxide degradation with GC-MS analysis is a degradative technique which cleaves $\beta$-O-4 links between the lignin groups and allows the quantification of cinnamic acids (Chang \& Allen, 1971; Hedges \& Ertel, 1982; Goñi \& Hedges, 1992). ${ }^{13} \mathrm{C}$ NMR is a useful technique for analysing insoluble material, because it avoids the artefacts generated by degradative techniques (Fidalgo et al., 1993). In the case of straw lignin, additional problems arise from the structural complexity of the APPL through the presence of $p$-hydroxyphenyl, guaiacyl and syringyl units in association with cinnamic acids. There are several studies which establish differences between APPL harvested from different residues by different micro-organisms (Borgmeyer \& Crawford, 1985; Trigo \& Ball, 1994; McCarthy et al., 1986; Ramachandra et al., 1988; Ball et al., 1990), but it is important to consider the method used for obtaining lignin-carbohydrate complexes (APPL) from both inoculated and control samples. For APPL extraction from solid-state fermentation of corn stover lignocellulose, both water and $\mathrm{NaOH}$ have been used (Crawford \& Pometto, 1988), and for this study we compared the extraction of APPL by these solvents, in order to assess the potential for using biological solubilization techniques, based on the use of streptomycetes, in relation to chemical solubilization techniques. Both degradative ( $\mathrm{CuO}$ oxidation) and non-degradative (IR and NMR) techniques were combined to study the solubilization of wheat straw during solid-state fermentation of straw by four Streptomyces strains.

\section{MATERIALS AND METHODS}

Micro-organisms and growth conditions. Three Streptomyces strains, Streptomyces chattanoogensis UAH 23 and Streptomyces sp. UAH 52 and UAH 33 were selected in our laboratory for their ability to degrade lignocellulosic residues. Streptomyces viridosporus strain T7A, a well-characterized lignocellulose-degrading actinomycete (Crawford et al., 1983) was used as a control throughout. All the strains were grown on GAE agar, containing $\left(\mathrm{I}^{-1}\right)$ : glucose, $10 \mathrm{~g}$; L-asparagine, $1 \mathrm{~g}$; yeast extract (Difco), $0.5 \mathrm{~g} ; \mathrm{K}_{2} \mathrm{HPO}_{4}, 0.5 \mathrm{~g} ; \mathrm{MgSO}_{4} . \mathrm{H}_{2} \mathrm{O}$,
$0.5 \mathrm{~g} ; \mathrm{FeSO}_{4} \cdot \mathrm{H}_{2} \mathrm{O}, 0.01 \mathrm{~g}$. Streptomyces viridosporus, and strains UAH 23 and UAH 52 were incubated at $28^{\circ} \mathrm{C}$, and strain UAH 33 at $37^{\circ} \mathrm{C}$. The strains were stored as spore suspensions in $20 \%(\mathrm{v} / \mathrm{v})$ glycerol at $-20^{\circ} \mathrm{C}$.

For experiments, spores were harvested from GAE agar dishes with distilled water containing Tween $80(0.01 \%)$, and a standard spore suspension $\left(5 \mathrm{ml}, 10^{-7}\right.$ c.f.u. $\left.\mathrm{ml}^{-1}\right)$ was used to inoculate flasks containing $150 \mathrm{ml}$ of mineral basal medium (MBM; Crawford, 1978) supplemented with $0.6 \%$ yeast extract.

Wheat straw (Triticum aestivum var. maestro) was ground in a Janke and Kunkel A-10 mill to pass through a 40-mesh screen and air-dried for $24 \mathrm{~h}$ at $50^{\circ} \mathrm{C}$. To facilitate the colonization of the substrate unplugged 21 flasks containing $10 \mathrm{~g}$ wheat straw were steamed for $1 \mathrm{~h}$ (Berrocal et al., 1996). The flasks were plugged with cotton stoppers and autoclaved for $20 \mathrm{~min}$ at $120^{\circ} \mathrm{C}$.

Cultures were incubated for $48 \mathrm{~h}$ with shaking at 200 r.p.m. and the mycelia harvested by centrifugation $(10000 \mathrm{~g}, 15 \mathrm{~min})$. For optimal solid-substrate fermentation conditions the mycelium from each flask was resuspended in $50 \mathrm{ml} \mathrm{MBM}$ and then used to inoculate wheat straw (10 g) (Berrocal et al., 1996). Cultures were incubated statically for $28 \mathrm{~d}$. Uninoculated controls were incubated as above.

Extraction of APPL. APPL was extracted from solid-substrate fermentation cultures after $28 \mathrm{~d}$ growth by the addition of $400 \mathrm{ml} \mathrm{NaOH}(0 \cdot 1 \mathrm{M})$ or distilled water. Samples were then steamed at $100{ }^{\circ} \mathrm{C}$ for $1 \mathrm{~h}$, filtered through Whatman no. 54 filter paper and washed again with $400 \mathrm{ml} \mathrm{NaOH}(0 \cdot 1 \mathrm{M})$ or distilled water at $60^{\circ} \mathrm{C}$. Supernatants were acidified with $\mathrm{HCl}$ $(12 \mathrm{M})$ to $\mathrm{pH} 1-2$ and the APPL harvested by centrifugation $(12000 \mathrm{~g}, 10 \mathrm{~min})$. Finally, the APPL was washed twice with distilled water ( $\mathrm{pH} 5)$ and freeze-dried.

Yield of APPL was expressed as a percentage of the freezedried APPL per $g$ wheat straw. Klason lignin was estimated as the ash-free residue after Saeman's hydrolysis of APPL (Effland, 1977). Ash content was determined after treatment at $575^{\circ} \mathrm{C}$ for $6 \mathrm{~h}$.

Cupric oxide degradation. Samples (100 g) of APPL obtained by $\mathrm{NaOH}$ or distilled water extraction were maintained at $180^{\circ} \mathrm{C}$ for $3 \mathrm{~h}$ in nitrogen Teflon bombs containing $\mathrm{CuO}(2 \mathrm{~g})$, $\mathrm{Fe}\left(\mathrm{NH}_{4}\right)_{2}\left(\mathrm{SO}_{4}\right)_{2} \cdot 6 \mathrm{H}_{2} \mathrm{O}(200 \mathrm{mg})$ and $14 \mathrm{ml}$ boiled $\mathrm{NaOH}$ (2 M). After precipitation with $\mathrm{HCl}(12 \mathrm{M})$, degradation products were recovered with 3 vols diethyl ether $(20 \mathrm{ml})$ and dried under nitrogen. Pyridine $(100 \mu \mathrm{l})$ was added to the dried residues and $25 \mu \mathrm{l}$ derivatized (silylated) with $40 \mu \mathrm{l}$ bis(trimethylsilyl)-trifluoroacetamide (BSTFA). The mixture was heated at $60^{\circ} \mathrm{C}$ for $10 \mathrm{~min}$ with periodic shaking to dissolve residues. Chromatographic analyses of APPL were carried out in a Perkin-Elmer Sigma 3B gas chromatograph, coupled to an electron-impact mass detector (ITD). Trimethylsilyl derivatives were separated in a SPB-1 capillary column (Supelco $0.25 \mu \mathrm{m}$ stationary-phase thickness, $30 \mathrm{~m} \times 0.25 \mathrm{~mm}$ i.d.). Nitrogen was used as carrier gas. Initial column oven temperature was $100^{\circ} \mathrm{C}$; the temperature was increased at $4^{\circ} \mathrm{C} \min ^{-1}$ to a final value of $270^{\circ} \mathrm{C}$.

Quantifications were based on the area of the internal standard (ethyl vanillone) and the response factors obtained from standard compounds [three $p$-hydroxyphenyls ( $p$-hydroxybenzaldehyde, $p$-hydroxyacetophenone, $p$-hydroxybenzoic acid); three guaiacyl compounds (vanillin, acetovanillone and vanillic acid); three syringyl compounds (syringaldehyde, acetosyringone and syringic acid); trans-ferulic acid and $p$ - 
coumaric acid] silylated as above. Amounts of lignin degradation products were calculated as molar quantities.

${ }^{13} \mathrm{C}$ NMR. High-resolution solid-state ${ }^{13} \mathrm{C}$ NMR spectroscopy was performed on freeze-dried samples of APPL from the uninoculated control and APPL obtained from wheat straw inoculated with S. chattanoogensis UAH 23, Streptomyces strains UAH 52 and UAH 33 and S. viridosporus. ${ }^{13} \mathrm{C}$ NMR spectra were obtained using cross-polarization and magicangle spinning (CPMAS) at $75 \mathrm{MHz}$ in a Varian Unity 300 spectrometer. The pulse repetition rate was $5.5 \mathrm{~s}$ and crosspolarization contact time was $3.5 \mathrm{~ms}$. Magic-angle spinning was $5 \cdot 3 \mathrm{kHz}$. All samples were analysed at room temperature. Areas of the chemical shift regions were expressed as percentages of total area (relative intensity).

IR spectroscopy. Each sample of APPL (3 mg) was homogenized with $\mathrm{KBr}(297 \mathrm{mg})$ and the disc analysed in an IR-TF (Nicolet, model SDXE) spectrophotometer with the spectra recorded between 400 and $2000 \mathrm{~cm}^{-1}$.

\section{RESULTS AND DISCUSSION}

\section{APPL production}

All four strains grown on wheat straw under solid-state fermentation conditions showed good colonization of the substrate and were able to produce the soluble lignin-carbohydrate complex (APPL) in yields greater than the uninoculated control (Table 1). These results again confirm the ability of streptomycetes to solubilize lignocarbohydrate from straw (Crawford et al., 1982; McCarthy et al., 1986; Pasti et al., 1990). The highest yield of APPL was obtained with $S$. chattanoogensis strain $\mathrm{UAH} 23$ when $\mathrm{NaOH}$ was used for extraction; the yield of APPL $\left[163 \pm 14 \mathrm{mg}\right.$ (g wheat straw) $\left.^{-1}\right]$ was $>180 \%$ that obtained from uninoculated straw. Yields obtained from the other strains varied between 141 and $143 \mathrm{mg} \mathrm{g}^{-1}$. The APPL yields obtained from straw extracted with distilled water were significantly lower, ranging from $6 \pm 0 \cdot 5$ to $23 \pm 2 \mathrm{mg} \mathrm{g}^{-1}$ for uninoculated straw and straw inoculated with Streptomyces strain UAH 33 respectively (Table 1 ). Previous values obtained for APPL production by actinomycetes grown in submerged culture using wheat straw as the main carbon and energy source have been reported to vary between 12 and $65 \mathrm{mg} \mathrm{g}^{-1}$ in one study of a range of actinomycetes (Ball et al., 1990), and $72 \mathrm{mg} \mathrm{g}^{-1}$ for Thermomonospora mesophila (McCarthy et al., 1986).

The highest yields of Klason lignin, expressed as a percentage of the total Klason lignin in the original substrate $(24.5 \pm 0.25 \%)$, were obtained from straw inoculated with Streptomyces strain $23(13.5 \pm 0.19 \%$ extracted with $\mathrm{NaOH}$ ) and $S$. chattanoogensis strain 33 $(1.8 \pm 0.06 \%$ extracted with distilled water $)$. It was concluded that after growth of the strains the amount of Klason lignin in the APPL was always higher than in uninoculated straw, regardless of the extraction method used. In APPL extracted with $\mathrm{NaOH}$, the ash content was always greater in inoculated straw, while in APPL extracted with water, the ash content varied between strains (Table 1).

\section{CuO oxidation}

GC-MS chromatograms obtained after $\mathrm{CuO}$ oxidation of the solubilized lignocarbohydrate from the uninoculated straw extracted with distilled water and $\mathrm{NaOH}$ are presented in Fig. 1 along with chromatograms of APPL from inoculated straw extracted with water. Cinnamic acids (peaks 11 and 12) and products derived from $p$ hydroxyphenyl $(\mathrm{H})$ units (peaks 1,2 and 6), guaiacyl $(G)$ units (peaks 3, 5 and 9) and syringyl (S) units (peaks 7, 8 and 10) were identified in all of the samples (Fig. 1). The molar $H: G: S$ relationship, $S / G$ ratio and cinnamic acid content were calculated for APPL extracted with both $\mathrm{NaOH}$ and distilled water (Table 2).

The S/G ratio of APPL from uninoculated straw with $\mathrm{NaOH}$ was 1.9 . The high $\mathrm{S}$ value is a characteristic of less condensed lignins, which are readily alkalineextractable (Lapierre \& Monties, 1989). The S/G ratio of APPL from straw inoculated with Streptomyces

Table 1. Yield, Klason lignin and ash content of APPL preparations extracted with $\mathrm{NaOH}$ and water from wheat straw inoculated with Streptomyces strains

Results are the means of triplicate assays $\pm S D$.

\begin{tabular}{|c|c|c|c|c|c|c|}
\hline \multirow[t]{2}{*}{ Inoculum } & \multicolumn{2}{|c|}{ Yield [mg (g wheat straw) $\left.)^{-1}\right]$} & \multicolumn{2}{|c|}{ Klason lignin $(\%)^{*}$} & \multicolumn{2}{|c|}{ Ash $(\%) \dagger$} \\
\hline & $\mathrm{NaOH}$ & Water & $\mathrm{NaOH}$ & Water & $\mathrm{NaOH}$ & Water \\
\hline Uninoculated control & $68 \pm 0 \cdot 5$ & $6 \pm 0.5$ & $4.73 \pm 0.03$ & $0 \cdot 37 \pm 0 \cdot 01$ & $0.06 \pm 0.006$ & $0.03 \pm 0.0005$ \\
\hline Streptomyces UAH 23 & $163 \pm 14$ & $20 \pm 1$ & $13 \cdot 49 \pm 0 \cdot 19$ & $1.69 \pm 0.05$ & $0 \cdot 30 \pm 0 \cdot 04$ & $0 \cdot 15 \pm 0 \cdot 02$ \\
\hline Streptomyces UAH 33 & $142 \pm 14$ & $23 \pm 2$ & $11 \cdot 83 \pm 0 \cdot 17$ & $1.76 \pm 0.06$ & $0 \cdot 40 \pm 0 \cdot 03$ & $0.05 \pm 0.005$ \\
\hline Streptomyces UAH 52 & $143 \pm 15$ & $21 \pm 1 \cdot 8$ & $11 \cdot 46 \pm 0 \cdot 17$ & $1.56 \pm 0.05$ & $0.35 \pm 0.05$ & $0.03 \pm 0.007$ \\
\hline S. viridosporus & $141 \pm 16$ & $9 \pm 0.9$ & $11 \cdot 60 \pm 0 \cdot 15$ & $0.66 \pm 0.02$ & $0 \cdot 70 \pm 0 \cdot 07$ & $0 \cdot 01 \pm 0 \cdot 0015$ \\
\hline
\end{tabular}

* Results are expressed as percentage of total Klason lignin in wheat straw $(24 \cdot 5 \pm 0 \cdot 25 \%)$.

†Results are expressed as percentage of total ash in wheat straw $(2 \cdot 29 \pm 0.07 \%)$. 

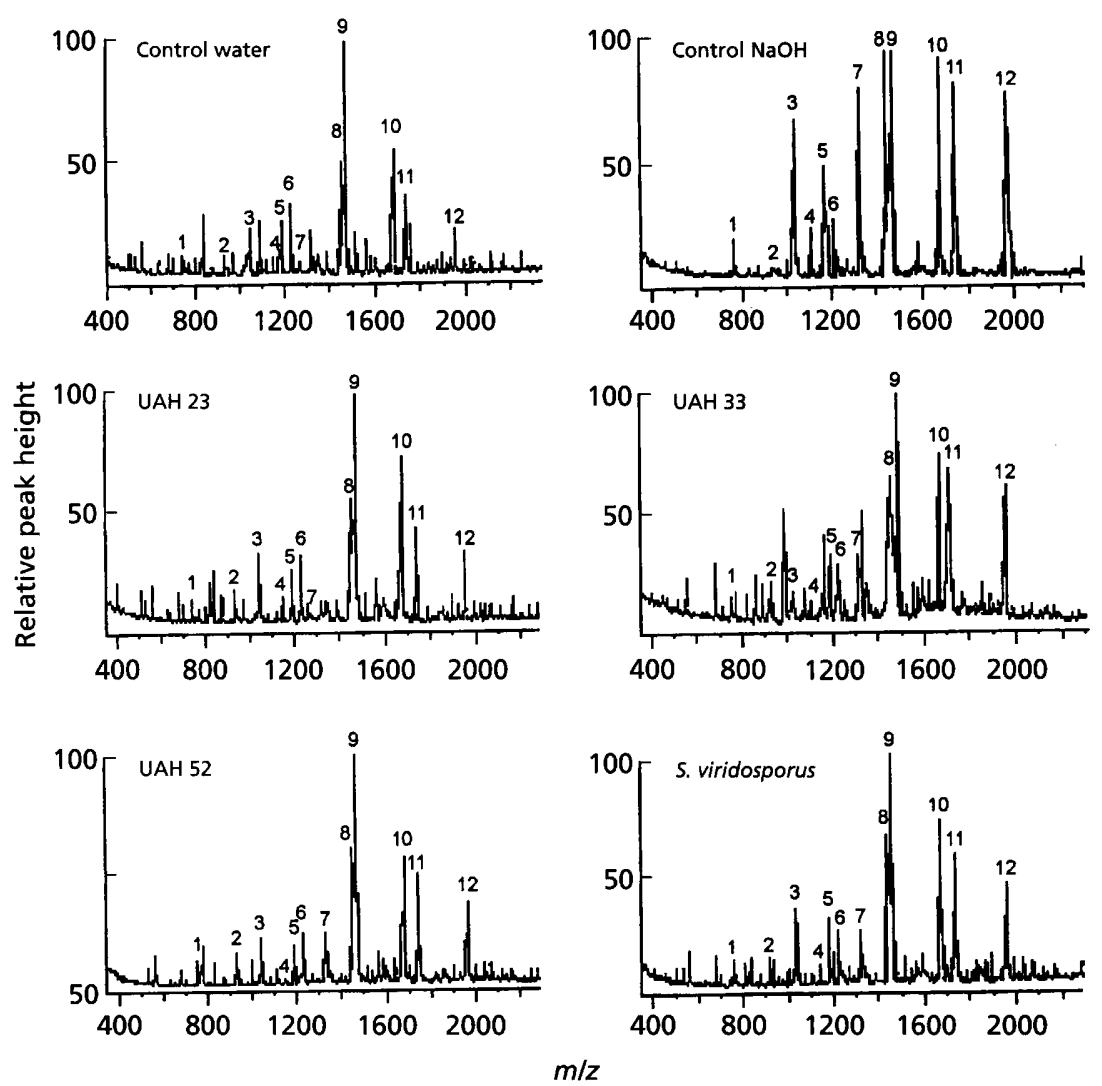

Fig. 1. GC-MS analysis of CuO degradation products of wheat straw extracted with distilled water and $\mathrm{NaOH}$ (controls) and APPL extracted with water from wheat straw inoculated with Streptomyces strains. Peak identification: $p$-hydroxybenzaldehyde (1); $p$-hydroxyacetophenone (2); vanillin (3); ethyl vanillin (4); acetovanillone (5); $p$ hydroxybenzoic acid (6); syringaldehyde (7); acetosyringone (8); vanillic acid (9); syringic acid (10); $p$-coumaric acid (11); trans-ferulic acid (12).

Table 2. Molar H:G:S relationship, S/G ratio and content of cinnamic acids determined after $\mathrm{CuO}$ oxidation of controls and APPL extracted with $\mathrm{NaOH}$ and water from wheat straw inoculated with Streptomyces strains

\begin{tabular}{|llccccc|}
\hline \multirow{2}{*}{ Extraction } & \multicolumn{1}{c}{$\begin{array}{c}\text { APPL } \\
\text { characteristic }\end{array}$} & \multicolumn{5}{c}{ Inoculum: } \\
\cline { 3 - 7 } & & Control* & UAH 23 & UAH 33 & UAH 52 & S. viridosporus \\
\hline \multirow{2}{*}{$\mathrm{NaOH}$} & $\mathrm{H}: \mathrm{G}: \mathrm{S}$ & $3: 33: 64$ & $5: 38: 57$ & $3: 42: 55$ & $5: 37: 58$ & $4: 34: 62$ \\
& $\mathrm{~S} / \mathrm{G}$ & $1 \cdot 9$ & $1 \cdot 5$ & $1 \cdot 3$ & $1 \cdot 5$ & $1 \cdot 7$ \\
& $p$-Coumarict & $5 \cdot 5$ & $5 \cdot 5$ & 5 & $4 \cdot 2$ & $4 \cdot 1$ \\
& trans-Ferulict & $14 \cdot 3$ & $17 \cdot 5$ & $9 \cdot 5$ & $10 \cdot 9$ & $12 \cdot 8$ \\
& $\mathrm{H}: \mathrm{G}: \mathrm{S}$ & $11: 34: 55$ & $12: 44: 44$ & $6: 39: 55$ & $10: 35: 54$ & $12: 44: 44$ \\
& $\mathrm{~S} / \mathrm{G}$ & $1 \cdot 6$ & 1 & $1 \cdot 4$ & $1 \cdot 5$ & 1 \\
& p-Coumarict & $7 \cdot 1$ & $8 \cdot 8$ & $11 \cdot 9$ & $12 \cdot 7$ & $11 \cdot 8$ \\
& trans -Ferulict & $3 \cdot 9$ & $6 \cdot 1$ & $13 \cdot 2$ & $15 \cdot 6$ & $10 \cdot 2$ \\
\hline
\end{tabular}

"Uninoculated wheat straw extracted with distilled water and $\mathrm{NaOH}$.

$\uparrow$ Mol per $100 \mathrm{~mol}$ lignin etherified $(H+G+S)$.

strain 33 showed the lowest ratio (1.3, Table 2), indicating degradation of the syringyl moieties by this strain. The low proportion of $\mathrm{H}$ units detected in all APPL samples extracted with $\mathrm{NaOH}$ suggests that many of the $\mathrm{H}$-lignin bonds are esters which are saponified during extraction with $\mathrm{NaOH}$ (Fidalgo et al., 1993).
The ferulic acid content of APPL extracted with $\mathrm{NaOH}$ was always greater than the coumaric acid content, with the highest values detected in APPL from $S$. chattanoogensis strain UAH $23(17.5$ and $5.5 \%$ for ferulic and coumaric acid respectively). Analyses of undegraded wheat straw have shown that the concentration of 


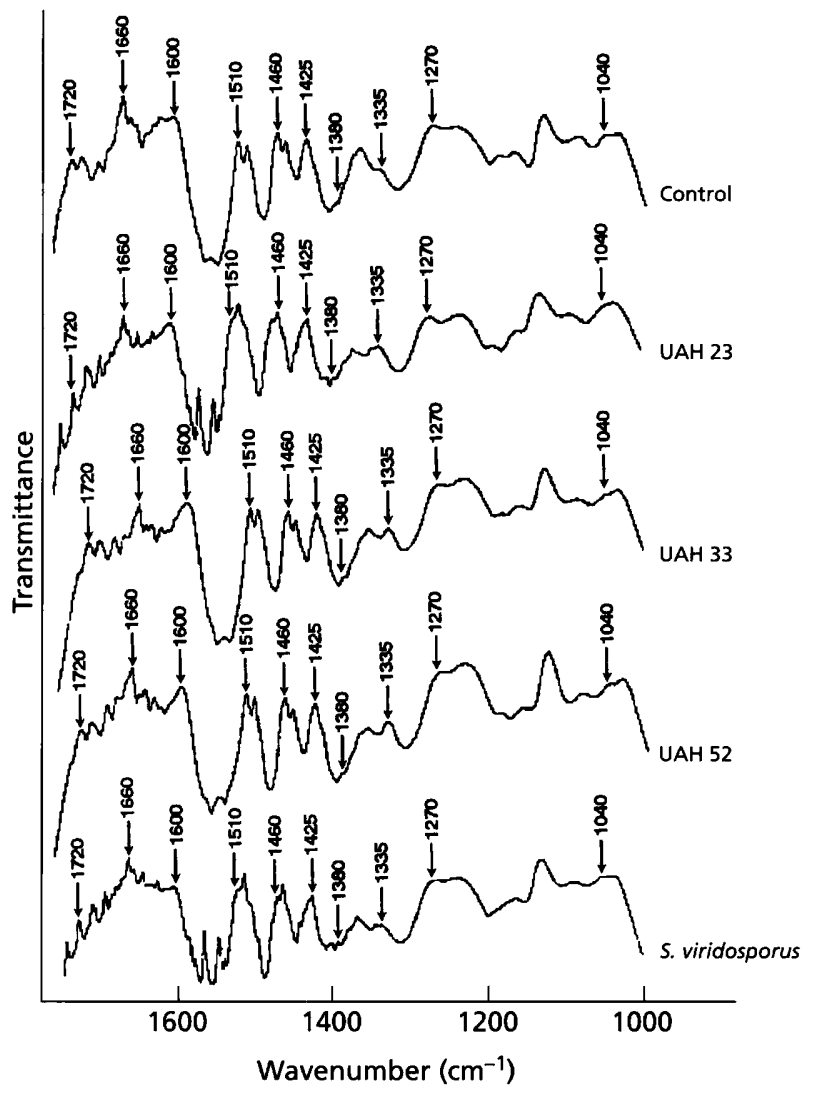

Fig. 2. IR spectra of APPL extracted with water from wheat straw inoculated with Streptomyces strains. Control is uninoculated wheat straw extracted with distilled water.

ferulic acid is generally higher than the concentration of coumaric acid (Hartley, 1972; Mueller-Harvey et al., 1986; liyama et al., 1990). In addition, ferulic acid may be cross-linked between lignin and hemicellulose by esterification of its carboxyl groups with the hydroxy groups of the arabinose residue in hemicellulose and by etherification of its phenolic hydroxyl groups with phenyl hydroxyls of lignin (Jeffries, 1990). Enzyme activities produced by streptomycetes involved in the cleavage of ether linkages (Ramachandra et al., 1988) or ester linkages (Christov \& Prior, 1993) in lignocellulose residues have been described. The difference between the ferulic acid content of the APPL extracted with water from inoculated and uninoculated straw may be attributed to the production of these activities by the streptomycetes studied.

Comparing the molar $\mathrm{H}: \mathrm{G}: \mathrm{S}$ relationship between APPL extracted with distilled water and $\mathrm{NaOH}$, $p$-hydroxyphenyl groups were much higher in APPL extracted with water, confirming that these units are mainly ester-linked to lignin (Fidalgo et al., 1993). The S/G ratio of APPL from inoculated straw was always lower than that of the APPL extracted from the control straw, with APPL from S. viridosporus and S. chattanoogensis UAH 23 exhibiting the lowest S/G values
$(\mathrm{S} / \mathrm{G}=1 \cdot 0$, Table 2$)$. The highest ferulic acid concentrations were detected in APPL from Streptomyces strain UAH $52(15 \cdot 6$ and $10 \cdot 9 \%$ respectively, Table 2$)$. The increased concentration of coumaric acid, but not ferulic acid, in APPL extracted with water in comparison to $\mathrm{NaOH}$-extracted APPL confirms the suggestion that coumaric acid in wheat straw is mainly ester-linked to lignin while ferulic acid is mainly ether-linked (Scalbert et al., 1985; Iiyama et al., 1990). Saponification of these ester links occurs during $\mathrm{NaOH}$ extraction leaving only the ether links, thereby decreasing the amount of coumaric acid recovered (Billa \& Monties, 1995). In contrast, ferulic acid complexes are mainly bound to the lignin in cell walls of wheat straw via ether links, and as these bonds are not disrupted by extraction with $\mathrm{NaOH}$, the concentration of ferulic acid detected was greater (Table 2). The increase in coumaric acid, and perhaps to a lesser extent ferulic acid, in APPL extracted with water from inoculated wheat straw when compared to the control APPL may be as a consequence of the action of phenolic acid esterases, enzymes which have been detected in culture supernatants from streptomycetes grown on media containing wheat straw (Deobald \& Crawford, 1987; Donnelly \& Crawford, 1988; Christov \& Prior, 1993). Alternatively, the increase in ferulic acid detected in APPL extracted with water from inoculated straw may be due to the formation of ferulic acid complexes which prevent extraction with water (but not $\mathrm{NaOH}$ ) from uninoculated straw (Jeffries, 1990). However, during microbial solubilization, the ester links of the ferulic acid could be cleaved, perhaps by ferulic acid esterase (Christov \& Prior, 1993) thus enabling the ferulic acid, which remains ether linked to the lignin, to be solubilized.

\section{IR spectroscopy}

IR spectra of APPL from inoculated wheat straw and the uninoculated control using water are presented in Fig. 2. The assignments of the most characteristic IR signals have been made in accordance with previous studies (Scalbert et al., 1986; Xiao-An et al., 1989; Fidalgo et al., 1993). The spectra are generally similar, with the most prominent bands corresponding to lignin $(1600,1510$, $1460,1425,1335$ and $1270 \mathrm{~cm}^{-1}$ ). Carbohydrate signals were detected at 1380 and $1040 \mathrm{~cm}^{-1}$, although no differences in these signals could be detected in APPL from inoculated and control spectra (Fig. 2). Bands from carbonyl groups were present at $1720 \mathrm{~cm}^{-1}$ (nonconjugated carbonyl groups, e.g. aliphatic acids, cinnamic acids and fatty acids) and $1660 \mathrm{~cm}^{-1}$ (conjugated carbonyl groups of amides) (Fengel \& Wegener, 1984). The broad band between 1620 and $1600 \mathrm{~cm}^{-1}$, assigned to the tension of the aromatic rings, is more intense in the APPL extracted from straw inoculated with Streptomyces strains UAH 23, UAH 33 and UAH 52, reflecting the greater lignin content of the APPL from these strains. The decrease in the intensity of the signals at 1510 and $1460 \mathrm{~cm}^{-1}$ in the IR spectra from APPL extracted from cultures of $S$. viridosporus and S. chattanoogensis UAH 23 suggests a loss of aryl radicals in the lignin side-chain, 


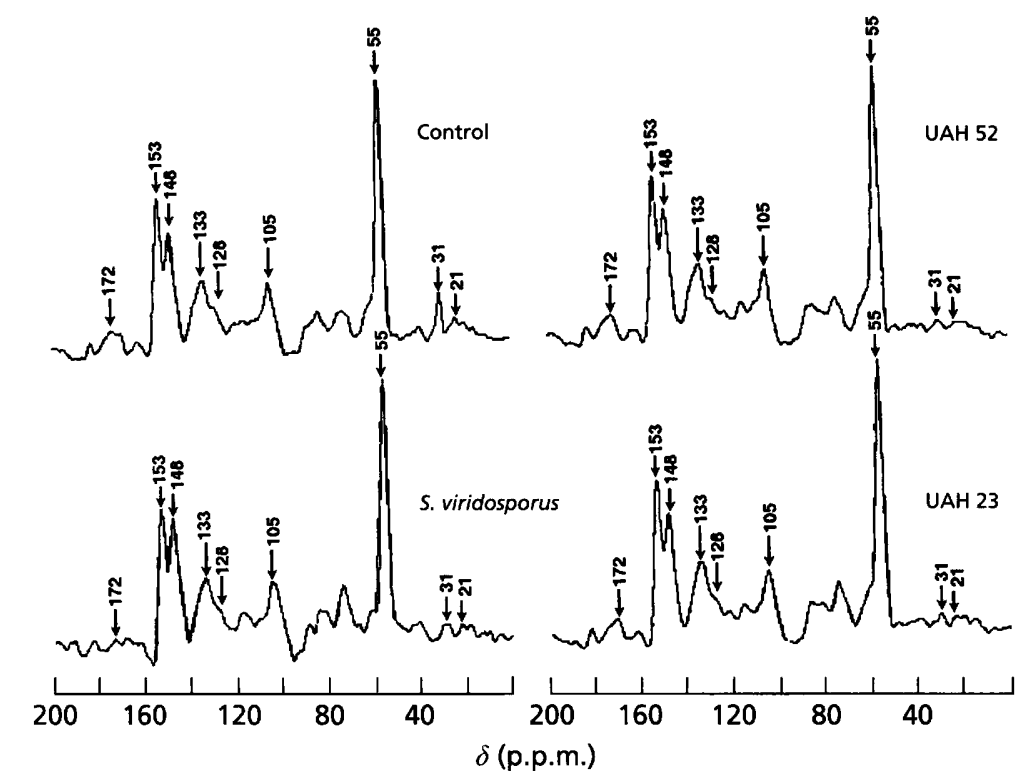

Fig. 3. CPMAS ${ }^{13} \mathrm{C}$ NMR spectra of APPL extracted with $\mathrm{NaOH}$ from wheat straw inoculated with Streptomyces strains. Control is uninoculated wheat straw extracted with $\mathrm{NaOH}$.

perhaps as a consequence of microbial activity (Almendros et al., 1992).

The differences between signals corresponding to 1510 , 1460 and $1335 \mathrm{~cm}^{-1}$ in the spectra of APPL extracted from wheat straw inoculated with $S$. chattanoogensis UAH 23 and S. viridosporus correspond to alterations in the lignin structure, mainly in the $S$ units, supporting the data obtained by $\mathrm{CuO}$ (Table 2). IR spectra of APPL extracted from control and inoculated wheat straw extracted with $\mathrm{NaOH}$ were poorly defined, probably due to the effects of $\mathrm{NaOH}$ on the ester linkages between the main structural moieties of wheat straw (data not shown).

\section{Solid-state CPMAS ${ }^{13} \mathrm{C}$ NMR}

NMR spectra of the APPL from control and inoculated wheat straw extracted with $\mathrm{NaOH}$ and water are shown in Fig. 3 and Fig. 4 respectively. Integration of spectral areas corresponding to different carbon types in the CPMAS ${ }^{13} \mathrm{C}$ NMR spectra are shown in Table 3 . Because of the similarity between spectra obtained from APPL extracted from wheat straw inoculated with Streptomyces strains UAH 52 and UAH 33, only spectra for strain UAH 52 are presented in Fig. 3. The assignments of the most prominent NMR signals have been made in accordance with previous studies (Lüdemann \& Nimz, 1973; Maciel et al., 1985; Scalbert et al., 1986; Almendros et al., 1992).

For lignin, 153 p.p.m. corresponds to the $C_{3}$ and $C_{5}$ in syringyl groups (S-etherified), 148 p.p.m. indicates the $\mathrm{C}_{3}$ and $\mathrm{C}_{4}$ in guaiacyl $(G)$ units (etherified) and 146 p.p.m. corresponds to the $C_{3}$ and $C_{5}$ in $S$ (phenolic) groups; 133 p.p.m. indicates $\mathrm{C}_{1}$ and $\mathrm{C}_{4}$ in $S$ and $\mathrm{C}_{1}$ in $\mathrm{G}$, 128 p.p.m. indicates the $C_{3}$ and $C_{6}$ groups in $p$ hydroxyphenyl (H), 105 p.p.m. corresponds to $C_{2}$ and $\mathrm{C}_{6}$ in $\mathrm{S}, 84$ p.p.m. indicates the $\mathrm{C}_{\beta}$ in $\beta-O-4$, and 55 p.p.m. corresponds to methoxy $C$. Several signals correspond to polysaccharide carbon units, 75 p.p.m. for $\mathrm{C}_{3}, \mathrm{C}_{2}$ and $\mathrm{C}_{5}$. Two other signals were present, 172 p.p.m. for carbonyl $C$ and 31 p.p.m. for nonsubstituted alkyl C. The signal at 21 p.p.m. corresponds to acetyl $\mathrm{C}$ from hemicellulose.

In NMR spectra for APPL extracted from inoculated wheat straw with $\mathrm{NaOH}$, the signal at 31 p.p.m. (nonsubstituted alkyl C) showed a decreased intensity compared with the signal from the uninoculated control. In all spectra the signal at 153 p.p.m., corresponding to $\mathrm{C}_{3}$ and $\mathrm{C}_{5}$ in $\mathrm{S}$, was greater than the signal at 148 p.p.m., corresponding to the $\mathrm{C}_{3}$ and $\mathrm{C}_{4}$ signal in $\mathrm{G}$. This confirms the data obtained from $\mathrm{CuO}$ oxidation of APPL indicating that the concentration of $S$ units is always greater than the concentration of $G$ units. No significant differences in the intensity of signals between 200 and 160 p.p.m. and between 21 and 0 p.p.m. could be detected in APPL extracted from inoculated straw, possibly due to cleavage of the ester links during $\mathrm{NaOH}$ extraction of APPL. The low $\mathrm{H}$ concentration of $\mathrm{NaOH}$ extracted APPL was also confirmed by NMR with the appearance of the signal at 128 p.p.m. as only a shoulder (Fig. 3). No differences in the signal obtained at 55 p.p.m. (corresponding to methoxy groups) could be detected between APPL from control and inoculated straw, suggesting that these strains do not demethylate lignin during growth on straw.

In NMR spectra of APPL from inoculated straw extracted with water, the signal corresponding to the carbonyl groups (172 p.p.m.) was decreased with respect to the spectra of the control APPL. However in a study by McCarthy et al. (1986) an increase in the signal at 172 p.p.m. of APPL extracted from straw after $14 \mathrm{~d}$ growth in submerged culture of Thermomonospora mesophila was observed. This increase in signal intensity was explained in terms of the ability of T. mesophila to oxidise the $\alpha$-carbons in the lignin propanoid chains, a reaction which would be expected to improve lignin solubility (McCarthy et al., 1986). Nevertheless, it is 


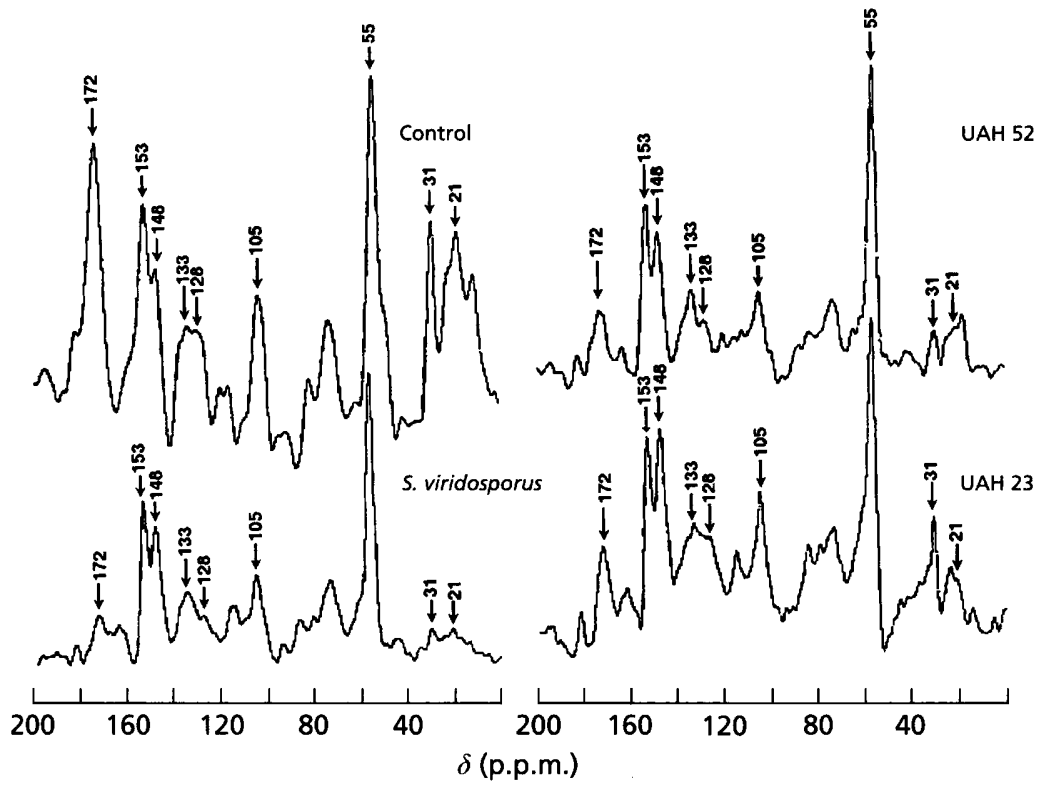

Fig. 4. CPMAS ${ }^{13} \mathrm{C}$ NMR spectra of APPL extracted with water from wheat straw inoculated with Streptomyces strains. Control is uninoculated wheat straw extracted with distilled water.

Table 3. Carbon composition from integration of CPMAS ${ }^{13} \mathrm{C}$ NMR spectra of controls and APPL extracted with $\mathrm{NaOH}$ and water from wheat straw inoculated with Streptomyces strains

\begin{tabular}{|c|c|c|c|c|c|}
\hline \multirow[t]{2}{*}{ Extraction } & \multirow[t]{2}{*}{ Inoculum } & \multicolumn{4}{|c|}{ Percentage of total carbon of: } \\
\hline & & $\begin{array}{c}\text { Carboxyl C } \\
(210-160 \text { p.p.m. })\end{array}$ & $\begin{array}{c}\text { Aromatic C } \\
(160-110 \text { p.p.m. })\end{array}$ & $\begin{array}{c}\text { O-Alkyl C* } \\
\text { (110-46 p.p.m.) }\end{array}$ & $\begin{array}{c}\text { Alkyl C } \\
(46-0 \text { p.p.m. })\end{array}$ \\
\hline \multirow[t]{5}{*}{$\mathrm{NaOH}$} & Control $\dagger$ & $10 \cdot 60$ & $37 \cdot 00$ & $42 \cdot 40$ & $10 \cdot 00$ \\
\hline & UAH 23 & $7 \cdot 00$ & $40 \cdot 80$ & $44 \cdot 00$ & $8 \cdot 00$ \\
\hline & UAH 33 & $10 \cdot 00$ & $38 \cdot 40$ & $43 \cdot 80$ & $7 \cdot 80$ \\
\hline & UAH 52 & $11 \cdot 90$ & $39 \cdot 20$ & $41 \cdot 20$ & $7 \cdot 70$ \\
\hline & S. viridosporus & $8 \cdot 60$ & $40 \cdot 00$ & $43 \cdot 60$ & $7 \cdot 80$ \\
\hline \multirow[t]{5}{*}{ Water } & Control $\dagger$ & $24 \cdot 18$ & 17.63 & $27 \cdot 24$ & $30 \cdot 93$ \\
\hline & UAH 23 & $7 \cdot 00$ & $40 \cdot 00$ & $43 \cdot 70$ & $9 \cdot 30$ \\
\hline & UAH 33 & $8 \cdot 90$ & $37 \cdot 50$ & $42 \cdot 70$ & $10 \cdot 80$ \\
\hline & UAH 52 & 8.90 & $37 \cdot 00$ & 43.00 & $10 \cdot 90$ \\
\hline & S. viridosporus & $11 \cdot 30$ & $37 \cdot 30$ & $38 \cdot 30$ & $13 \cdot 00$ \\
\hline
\end{tabular}

* Oxygen-linked aliphatic C, including lignin methoxy groups.

†Uninoculated wheat straw extracted with distilled water and $\mathrm{NaOH}$.

difficult to attribute the variations in the intensity of this signal to the oxidation of the side chains of lignin, considering there are too many carbonyl groups which overlap this signal in ${ }^{13} \mathrm{C}$ NMR spectra (i.e. protein, aliphatic acids, cinnamic acids) (Almendros et al., 1992; Gamble et al., 1994; Reeves \& Schmidt, 1994). The variation in this signal must be confirmed by specific determination of the above mentioned compounds in APPL from uninoculated and inoculated wheat straw. The decrease in the signal at 21 p.p.m. in the APPL spectra from inoculated straw extracted with water provides further evidence for the existence of ferulic acid and coumaric acid esterases, although this has yet to be confirmed by enzyme studies.

Changes in the signals at 153 p.p.m. (corresponding to the $S$ units) and at 148 p.p.m. (G) in the spectrum from APPL obtained from inoculated wheat straw correspond to changes in the $S / G$ ratio as determined by $\mathrm{CuO}$ oxidation. The increased concentration of $\mathrm{H}$ units in the APPL extracted with water compared with APPL extracted with $\mathrm{NaOH}$ was clearly evident in the signal intensity at 128 p.p.m. No differences in the intensity of the signal at 55 p.p.m. could be detected in APPL extracted with water, confirming the results obtained by McCarthy et al. (1986) with Thermomonospora mesophila.

One limitation in the use of NMR spectra is the inability to distinguish between the hemicellulose and cellulosic components of APPL because of the overlap between resonance signals (Gamble et al., 1994). However, in the 
110-46 p.p.m. region, significant modifications can be detected in APPL from inoculated straw. These modifications confirm the ability of streptomycetes to carry out simultaneous degradation of all the three main components of lignocellulose.

\section{Concluding remarks}

The complementary techniques used in this study allow the fullest interpretation of the results. NMR and IR allow the analysis of a relatively unaltered substrate. However, the complexity of APPL inevitably means that signals relating to different components of APPL overlap, complicating interpretation. $\mathrm{CuO}$ degradation is a relatively mild procedure for analysing straw lignin since it allows the estimation by GC-MS analysis of lignin units and cinnamic acids separately.

The results from the analysis of APPL using destructive and non-destructive techniques show that the properties of the APPL extracted by water and $\mathrm{NaOH}$ are very different. APPL obtained through $\mathrm{NaOH}$ extraction results in greater yields of the lignin part of the complex, but causes modifications in the APPL. The most significant alteration can be detected in the cinnamic acid and the aromatic moiety of lignin. The breaking of the ester links between hemicellulose and lignin and between hemicellulose and cinnamic acids decreases the number of alkyl and carbonyl groups present. The cleavage of these ester cross-linking groups by $\mathrm{NaOH}$ extraction enables the lignin to be more readily solubilized from the hemicellulose fraction. When APPL was extracted with water, ester links remain, allowing a better assessment of the process of solubilization by streptomycetes. The possible involvement of esterases and peroxidases in the lignocellulose solubilization could only be envisaged when water was used to harvest APPL.

We conclude through the study of APPL extracted with water that streptomycetes are able to modify the aromatic moiety of lignin during the solubilization process, with modifications occurring in the syringyl moieties. In addition the ability of streptomycetes to break the ester bond between cinnamic acids and hemicellulose can be inferred. However, for nonbiological studies, such as chemical processes, the use of $\mathrm{NaOH}$ for lignin solubilization (as is used in the paper and pulp industry) represents a more efficient process as higher APPL yields are obtained when compared to APPL extracted with water. The increased yields of APPL obtained when straw is first incubated with streptomycetes, followed by extraction with $\mathrm{NaOH}$ $(0 \cdot 1 \mathrm{M})$, suggest a possible role for these organisms or their enzymes to enhance alkali extractions in the industrial solubilization of lignocellulose.

\section{ACKNOWLEDGEMENTS}

This research was supported by CICYT project BIO 092-0375. We acknowledge with thanks the assistance of Dr F. J. Gonzalez-Vila, Instituto de Recursos Naturales y Agrobiología (CSIC), Sevilla (IR spectra), Dra A. Prieto, Centro de
Investigaciones Biológicas (CSIC), Madrid (GC-MS) and Dr M. Galajov (UCSA), Universidad de Alcalá (CPMAS ${ }^{13} \mathrm{C}$ NMR).

\section{REFERENCES}

Almendros, G., Martínez, A. T., González, A. E., González-Vila, F. J., Fründ, R. \& Lüdemann, H.-D. (1992). CPMAS ${ }^{13} \mathrm{C} N M R$ study of lignin preparations from wheat straw transformed by five lignocellulose-degrading fungi. J Agric Food Chem 40, 1297-1302.

Ball, A. S., Godden, B., Helvenstein, P., Penninckx, M. J. \& McCarthy, A. J. (1990). Lignocarbohydrate solubilization from wheat straw by actinomycetes. Appl Environ Microbiol 56, 3017-3022.

Berrocal, M., Hernández-Coronado, M., Hernández, M., Huerta, S., Rodriguez, J., Copa-Patiño, J., Soliveri, J., Pérez-Leblic, M. I. \& Arias, M. E. (1996). Chemical characterization of wheat straw transformed by selected Streptomyces strains and lignin related enzymes production in SSF process. In Biotechnology in the Pulp and Paper Industry: Advances in Applied and Fundamental Research, pp. 569-572. Edited by E. Srebotnik \& K. Messner. Vienna: Facultas-Universitätsverlag.

Billa, E. \& Monties, B. (1995). Molecular variability of lignin fractions isolated from wheat straw. Res Chem Intermed 21, 303-311.

Borgmeyer, J. R. \& Crawford, D. L. (1985). Production and characterization of polymeric lignin degradation intermediates from two different Streptomyces spp. Appl Environ Microbiol 49, 273-278.

Chang, H.-M. \& Allan, G. G. (1971). Oxidation. In Lignins: Occurrence, Formation, Structure and Reactions, pp. 433-485. Edited by K. V. Sarkanen \& C. H. Ludwing. New York: Wiley.

Christov, L. P. \& Prior, B. A. (1993). Esterases of xylan-degrading microorganisms : production, properties and significance. Enzyme Microb Technol 15, 460-475.

Crawford, D. L. (1978). Lignocellulose decomposition by selected Streptomyces strains. Appl Environ Microbiol 35, 1041-1045.

Crawford, D. L. \& Pometto, A. L., III (1988). Acid-precipitable polymeric lignin: production and analysis. Methods Enzymol 161, 35-47.

Crawford, D. L., Barder, M. J., Pometto, A. L., III \& Crawford, R. L. (1982). Chemistry of softwood lignin degradation by Streptomyces viridosporus. Arch Microbiol 131, 140-145.

Crawford, D. L., Pometto, A. L., III \& Crawford, R. L. (1983). Lignin degradation by Streptomyces viridosporus : isolation and characterization of a new polymeric lignin degradation intermediate. Appl Environ Microbiol 45, 898-904.

Dart, R. K. \& Betts, W. B. (1991). Uses and potential of lignocellulose. In Biodegradation: Natural and Synthetic Materials, pp. 201-217. Edited by W. B. Betts. London: Springer-Verlag.

Deobald, L. A. \& Crawford, D. L. (1987). Activities of cellulase and other extracellular enzymes during lignin solubilization by Streptomyces viridosporus. Appl Microbiol Biotechnol 26, 158-163.

Donnelly, P. K. \& Crawford, D. L. (1988). Production by Streptomyces viridosporus T7A of an enzyme which cleaves aromatic acids from lignocellulose. Appl Environ Microbiol 54, 2237-2244.

Effland, M. J. (1977). Modified procedure to determine acidinsoluble lignin in wood and pulp. Tappi 60, 143-144. 
Fengel, D. \& Wegener, G. (1984). Wood: Chemistry, Ultrastructure, Reactions. Berlin \& New York: Walter de Gruyter.

Fidalgo, M. L., Terrón, M. C., González, A. E., Martínez, A. T., González-Vila, F. J. \& Galletti, G. C. (1993). Comparative study of fractions from alkaline extraction of wheat straw through chemical degradation, analytical pyrolysis and spectroscopic techniques. J Agric Food Chem 41, 1621-1626.

Gamble, G. R., Sethuraman, A., Akin, D. E. \& Eriksson, K.-E. L. (1994). Biodegradation of lignocellulose in bermuda grass by white rot fungi analyzed by solid-state ${ }^{13} \mathrm{C}$ nuclear magnetic resonance. Appl Environ Microbiol 60, 3138-3144.

Goñi, M. A. \& Hedges, J. I. (1992). Lignin dimers: structures, distribution and potential geochemical applications. Geochim Cosmochim Acta 56, 4025-4043.

Hartley, R. D. (1972). p-Coumaric and ferulic acid components of cell walls of ryegrass and their relationships with lignin and digestibility. J Sci Food Agric 23, 1347-1354.

Hartley, B. S., Broda, P. \& Senior, P. (1987). Technology in the 1990s - Utilisation of Lignocellulosic Wastes. London: The Royal Society.

Hedges, J. I. \& Ertel, J. R. (1982). Characterization of lignin by gas capillary chromatography cupric oxide oxidation products. Anal Chem 54, 174-178.

liyama, K., Lam, T. B. \& Stone, B. A. (1990). Phenolic acid bridges between polysaccharides and lignin in wheat internodes. Pbytochem 29, 733-737.

Jeffries, T. W. (1990). Biodegradation of lignin-carbohydrate complexes. Biodegradation 1, 163-176.

Lapierre, C. \& Monties, B. (1989). Structural information gained from the thioacidolysis of grass lignins and their relation with alkali solubility. In TAPPI Proceedings of the International Symposium on Wood and Pulp Chemistry, Raleigh, pp. 615-621. Atlanta, GA: Tappi Press.

Lüdemann, H. D. \& Nimz, H. (1973). Carbon-13 nuclear magnetic resonance spectra of lignins. Biochem Biophys Res Commun 52, $1162-1169$.

Maciel, G. E., Haw, J. F., Smith, D. H., Gabrielsen, B. C. \& Hatfield, G. R. (1985). Carbon-13 nuclear magnetic resonance of herbaceous plants and their components, using cross polarization and magic-angle spinning. J Agric Food Chem 33, 185-191.

McCarthy, A. J. (1987). Lignocellulose-degrading actinomycetes. FEMS Microb Rev 46, 145-163.

McCarthy, A. J., Paterson, A. \& Broda, P. (1986). Lignin solu- bilization by Thermomonospora mesophila. Appl Microbiol Biotechnol 24, 347-352.

Mueller-Harvey, I., Hartley, R. D., Harris, P. J. \& Curzon, E. H. (1986). Linkage of $p$-coumaroyl and feruloyl groups to cell-wall polysaccharides of barley straw. Carbohydr Res 148, 71-85.

Pasti, M. B., Pometto, A. L., III, Nuti, M. P. \& Crawford, D. L. (1990). Lignin-solubilizing ability of actinomycetes isolated from termite gut. Appl Environ Microbiol 56, 2213-2218.

Ramachandra, M., Crawford, D. L. \& Hertel, G. (1988). Characterization of an extracellular lignin peroxidase of the lignocellulolytic actinomycete Streptomyces viridosporus. Appl Environ Microbiol 54, 3057-3063.

Reeves, J. B., III \& Schmidt, W. F. (1994). Solid-state ${ }^{13} \mathrm{C}$ NMR analysis of forage and byproduct-derived fiber and lignin residues. Resolution of some discrepancies among chemical, infrared, and pyrolysis-gas chromatography-mass spectroscopic analyses. $J$ Agric Food Chem 42, 1462-1468.

Scalbert, A., Monties, B., Lallemand, J. Y., Guittet, E. \& Rolando, C. (1985). Ether linkage between phenolic acids and lignin fractions from wheat straw. Phytochemistry 24, 1359-1362.

Scalbert, A., Monties, B., Lallemand, J. Y. \& Guittet, E. (1986). Comparison of wheat straw lignin preparations. I. Chemical and spectroscopic characterization. Holzforschung 40, 119-127.

Seelenfreund, D., Vicuña, R. \& Lapierre, C. (1990). Production of soluble lignin-rich fragments (APPL) from wheat lignocellulose by Streptomyces viridosporus and their partial metabolism by natural bacterial isolates. J Biotechnol 13, 145-158.

Trigo, C. \& Ball, A. S. (1994). Is the solubilized product from the degradation of lignocellulose by actinomycetes a precursor of humic substances? Microbiology 140, 3145-3152.

Winter, B., Fiechter, A. \& Zimmermann, W. (1991). Degradation of organochlorine compounds in spent sulfite bleach plant effluents by actinomycetes. Appl Environ Microbiol 57, 2858-2863.

Xiao-An, L., Zhong-Zheng, L. \& Die-Sheng, T. (1989). Fractional studies on the characteristics of high alkali-soluble lignins of wheat straw. Cellulose Chem Technol 23, 559-575.

Zhou, W., Winter, B. \& Zimmermann, W. (1993). Dechlorination of high molecular mass compounds in spelt sulfite bleach effluents by free and immobilized cells of Streptomyces. Appl Microbiol Biotechnol 39, 418-423.

Received 13 August 1996; revised 13 November 1996; accepted 2 December 1996. 